\title{
REFLECTION
}

\section{Finding Hope in the Face-to-Face}

\author{
Jennifer Y. C. Edgoose, $M D, M P H^{1}$ \\ Julian M. Edgoose, $P b D^{2}$ \\ 'Department of Family Medicine and \\ Community Health, University of \\ Wisconsin School of Medicine and Public \\ Health, Madison, Wisconsin
}

${ }^{2}$ School of Education, University of Puget Sound, Tacoma, Washington
Conflicts of interest: authors report none.

\section{CORRESPONDING AUTHOR}

Jennifer Y. C. Edgoose, MD, MPH Department of Family Medicine and Community Health

University of Wisconsin School of Medicine and Public Health

100 Delaplaine Ct.

Madison, WI 53715-1896

Jennifer.edgoose@fammed.wisc.edu

\begin{abstract}
What does it mean to look into the face of a patient who looks back? Face-toface encounters are at the heart of the patient-clinician relationship but their singular significance is often lost amid the demands of today's high-tech, metricdriven health care systems. Using the framework provided by the philosopher and Holocaust survivor Emmanuel Levinas, the authors explore the unique responsibility and potential for hope found only in face-to-face encounters. Revisiting this most fundamental attribute of medicine is likely our greatest chance to reclaim who we are as clinicians and why we do what we do.
\end{abstract}

Ann Fam Med 2017;15:272-274. https://doi.org/10.1370/afm.2076.

W e had nothing in common. She was from a small indigenous tribe in Mexico called the Triqui. We couldn't find a Triqui interpreter and my poor Spanish was no better than hers. Her face belied her age of only 17, due to years of work in the fields and suffering at the hands of an older man. She made the arduous journey north, arriving pregnant and undocumented, and now I was to be her doctor. Our worldviews were so different that even her way of expressing pain confounded me. I reverted to closed-ended questions about where, when, how, and why, but still felt lost gathering only incoherent answers and gestures. We struggled together during her gestation period and, despite being an experienced physician who can usually connect with challenging patients, I came to feel my heart sink every time I saw her name on my schedule. Toward the end of her pregnancy, tired of our inadequate words, I looked into her eyes and tried to give her hand a reassuring squeeze as we parted. Then, in broken Spanish, she asked me what I thought of the name "Edgoose." I was stunned into silence and eventually mumbled that my unusual last name would really not be appropriate for her expected daughter. .

\section{THE FACE-TO-FACE}

The daily work of clinicians is conducted in face-to-face encounters, whether in exam rooms, homes, or alongside hospital beds, but little attention has been paid to the responsibilities and ethical implications generated by this dimension of our relational work. The term "face-to-face encounter," indeed, has been co-opted by the Centers for Medicaid and Medicare Services to mean little more than a billing requirement for goods and services such as durable medical equipment or home health care. Yet what does it mean to look into the face of a patient who looks back? We believe this simple act causes many of the frustrations of current clinical practice, but also many of its most precious rewards. These rewards must be better understood and appreciated now, when medical technology and pressures of productivity are diminishing face-to-face encounters.

Lithuanian-born French philosopher, Emmanuel Levinas (1906-1995) offers a theoretical framework through which we can examine the essence of the face-to-face patient-doctor relationship. While his writings have been explored in the medical humanities literature, ${ }^{1-6}$ little has been writ- 
ten for practicing clinicians. Levinas's lens of the face-to-face can help us redefine our responsibility to patients and remind us why we chose this profession.

\section{PROXIMITY}

If we think of face-to-face interactions simply as those where a physician and patient meet in the same room to address health concerns, as if we were watching two people interact on a stage, we miss much about what makes these encounters so remarkable. Rather, to state the obvious, face-to-face encounters start when we look at a person who is looking back at us. We look into his or her eyes, but we do not see them in anything like the way that we see objects, or pictures (as, for example, we often don't notice their color). Once we have caught the patient's eye-perhaps saying hello or shaking hands-Levinas would say that we are now in proximity with them, that our lives are now linked.

The face is ethically compelling, Levinas claims, because within its finite perimeter there are an infinite number of possible responses. For example, a patient can respond to us with joy, fury, frustration, indifference, laughter...even love or loathing; or with a comment or insight that we could never have predicted. In this way, the patient is "Other" because he or she always resists our complete understanding: we can never quite know his or her thoughts, experiences, or what will be said next. As Charles Dickens wrote in A Tale of Two Cities, "every human creature is constituted to be that profound secret and mystery to every other." Thus, when we are in proximity with a patient, his or her face engages us, not metaphorically, but uniquely. It opens us to the Other and, as we'll explore next, serves as the fulcrum for responsibility.

\section{RESPONSIBILITY}

This sense of otherness is not confined to first encounters. Those we have known for our entire lives can still surprise us. Thus we must be ready and able to respond to our ever-evolving sense of what the Other means. This ongoing and necessary readiness and ability to respond is, Levinas claims, a response-ability, the origin of our feelings of responsibility. We do not leave an interaction with someone with the sense that everything is wrapped up and finished; our doubts and uncertainties continue to bind us in this ongoing partnership. This is a foundational aspect of primary care's valuing of continuous, sustained relationships.

Although our codes of professional ethics suggest that there are rational rules to explain the extent of our responsibility to patients and protect us from personal liability, Levinas is saying something far more complex.
He claims that we feel responsibility even from the smallest face-to-face interactions. Seen from this vantage, professional ethics seems more concerned with allowing us to ignore the more primal webs of responsibility that we feel.

This echoes Levinas's understanding of the Holocaust, in which he lost many family members. How could Germany, a highly advanced nation, commit such acts? He claims that Western ethics misunderstands the origins of responsibility. Since the Enlightenment, natural and social sciences have sought to catalog the world as knowledge and thus eliminate its Otherness. In the most extreme example, Nazis objectified Jews and other minorities to such an extent they were considered non-human, enabling genocide. To Levinas, in contrast, ethics begins when knowledge fails us. Indeed, history tells of many cases in which strangers (sometimes cardcarrying Nazis) acted to protect people in face-to-face interactions. It could be argued that they had decided it was their duty to protect the vulnerable, but Levinas argues that the origins of our sense of responsibility are more reflexive and less cognitive. In this way, he reclaims the Judaic understanding that we humans are ethical before we are rational.

The sense of responsibility that Levinas describes is problematic for clinicians who try to maintain control of these relationships and focus merely upon outcomes. Certainly, we are expected to utilize our expert skills and knowledge to achieve well-reasoned diagnoses and provide evidence-informed interventions and rational advice. Yet, ultimately, the outcome cannot be assured, in part, because of the unknowable response of the Other. If we try to battle this, we will lose, as we are battling something inescapable in face-to-face interactions.

While Levinas's view of responsibility might seem exhausting when confronted with someone we think of as challenging, such as my Triqui patient, it also opens us to perhaps the most sustaining aspect of medicine if we affirm this response-ability of our work.

\section{THE SAYING AND THE SAID}

We physicians often root our hope in our patients' outcomes, feeling confident when they recover, but thus we leave ourselves open to despair when outcomes are not good. Yet if we take seriously Levinas's assertion that the patient is Other, then we can never know where each face-to-face encounter will take us, or where it will take the patient. In fact, it is the shared journey, the ever-evolving process, which offers both patient and doctor an opportunity to grow, learn, and discover. Therein lies hope for patient and clinician alike. Even in the face of bad news, the persistent Otherness of the patient and the resulting uncertainties that 
haunt our face-to-face interactions ensure that what will emerge is beyond what either the patient or clinician could have predicted beforehand. We can be surprised at the patient's response and even by our own, as previously unspoken words of regret, anger, forgiveness, or longing emerge in the space between us and shape the understandings of us both.

This becomes particularly clear when we try to help patients confront the huge unknown and unknowable changes of aging, sickness, and death. Levinas writes that, at times like these, the saying-the fact that we are interacting face-to-face-is more important than the said, the words spoken. The Levinas scholar Alphonso Lingis writes about being at someone's deathbed: "you have to be there ... what you say, in the end, hardly matters...." In fact, silent presence, unobscured by words, may be the most powerful manifestation of the face-to-face.

These experiences only underline the untapped, unscripted potential of such encounters. The patient demands our presence and engagement. We are vulnerable to his or her agenda and to the unknowability of what is to come. The moments the clinician and patient share in the saying can lead to new alliances and understandings that outsiders may find hard to comprehend. In these profound moments, we bear witness to the relationship in an act of fidelity, not to the outcome, but to the Other. Our perspective shifts away from ourselves. It is here in this moment of deep empathic connection that many of us find hope and meaning that remains not only the patient's greatest solace but also the clinician's best remedy to burnout.

\section{A FINE RISK TO BE RUN}

While opening ourselves up to vulnerability may feel overwhelming, it is this stance that is essential to a fully embrace the responsibility of face-to-face interactions. Levinas writes, "Communication with the other can be transcendent only as a dangerous life, a fine risk to be run." ${ }^{\prime \prime}$ In our willingness to be open to the unexpected, to be surprised, we must relinquish control and give the gift of curiosity, or even suspended disbelief. It is here that we find ourselves doing the unexpected that is beyond rational thought. It is here when I found myself saying goodbye to a dear patient dying of cancer. She weakly hugged me and whispered "I love you, Dr Edgoose," and I kissed her on the cheek and whispered back, "I love you too, Karen."

\section{HOPE}

We physicians are immensely fortunate to be in a profession that is so rooted in face-to-face interactions, and yet much of the discourse in medicine seems to poorly understand this as an important dimension of our work, and of healing. We often lose sight of this perspective in our current world of endless electronic documentation; billing requirements and regulations; productivitybased compensation; and pay-for-performance measures. Even in an optimal telemedicine experience, we are still bereft of a complete relational vantage not fully knowing who else may be in the room and other important environmental circumstances. Without proximity, we lose sight of the ambiguities and uncertainties that are inescapable in the face-to-face, and the humanity and hope inherent in those relationships that can bring both patient and physician to new and unexpected ways of being. Thus, while the feelings of responsibility that emerge in face-to-face interactions can cause many of the frustrations of medicine, the mystery in each face is also a source of openness and possibility that can in itself bring hope to patients and clinicians alike.

.. One week after our last visit, my patient delivered a beautiful, healthy girl. She named her Jennifer. I now teach and practice 2,000 miles from the girl who was named after me. She is now be about 10 years old and I hope speaks Triqui and English. Despite a vast divide in language and culture, her mother and I found mutual compassion and hope bound in the face-to-face.

To read or post commentaries in response to this article, see it online at http:I/www.AnnFamMed.org/content/15/3/272I.

Key words: clinician-patient communication/relationship; psychosocial issues in health care; hope

Submitted September 27, 2016; submitted, revised, December 13, 2016; accepted January 16, 2017.

Acknowledgments: Special thanks to Doctors John Frey, Will Miller, Mindy Smith, and our 3 anonymous reviewers for their editorial support and encouragement.

\section{References}

1. Tiemersma D. Ontology and ethics in the foundation of medicine and the relevance of Levina's view. Theor Med. 1987;8(2):127-133.

2. Clifton-Soderstrom M. Levinas and the patient as other: the ethical foundation of medicine. J Med Philos. 2003;28(4):447-460.

3. Irvine CA. The other side of silence: Levinas, medicine, and literature. Lit Med. 2005;24(1):8-18.

4. Bennahum DA. On first reading Emmanuel Levinas. Camb $Q$ Healthc Ethics. 2013;22(4):420-424.

5. Levinas E. Ethics and Infinity: Conversations with Philippe Nemo. Pittsburgh, PA: Duquesne University Press;1985.

6. Levinas E. Difficult Freedom: Essays on Judaism. Hand S, transl. Baltimore, MD: Johns Hopkins University Press; 1997.

8. Lingis A. The Community of Those Who Have Nothing in Common. Bloomington: Indiana University Press, 1993.

9. Levinas E. Otherwise Than Being, Or, Beyond Essence. Pittsburgh, PA: Duquesne University Press; 1974. 